\title{
Micro-Raman Spectroscopy, Colour Stability, Roughness and Mass Variation of Removable Partial Dentures after Cleansing with White Wine Vinegar
}

\author{
Alene Silva Melo Araújo', Paula Ramalho Franca Flores ${ }^{1}$, Victor Pinheiro Feitosa*,1,2, Lídia Audrey Rocha Valadas ${ }^{1}$, Diego Martins de \\ Paula ${ }^{1,2}$, Nicole de Mello Fiallos ${ }^{1}$, Igor Ribeiro Rola ${ }^{3}$, José Antero Soares Rola ${ }^{1}$, Ana Cristina de Mello Fiallos ${ }^{1}$ \\ 'Department of Restorative Dentistry, Federal University of Ceara, Fortaleza, BRAZIL. \\ 2 Paulo Picanço College of Dentistry, Fortaleza, BRAZIL. \\ ${ }^{3}$ Dentistry College, University of Fortaleza, Fortaleza, BRAZIL.
}

\begin{abstract}
Objective:The aim of this study was to analyze the invitroeffect of WhiteWine Vinegar (WWV) on surface properties of removable partial dentures' (RPD) components. Methods: Thirty specimens of one artificial teeth and a slab of cobalt-chromium alloy for RPDs were prepared. Specimens were distributed randomly in 3 groups $(n=10)$ : distilled water (negative control), WWV and CoregaTabs ${ }^{\circledR}$ (commercial control). Before and after immersion regimens, the analyses undertaken were colour stability assessed using spectrophotometer, mean roughness surveyed by perfilometry, mass variation using an analytical balance and surface composition assessed by Raman micro-spectroscopy. The data were statistically analyzed by repeated-measures ANOVA and Tukey test $(p<0.05)$. Results: No statistically significant differences were observed between the treatments on roughness and colour change. Distilled water increased the weight of specimens whilst CoregaTabs and WWV reduced significantly the mass $(p<0.05)$. In the Raman analysis, reduction of Co-Cr peak at $470 \mathrm{~cm}^{-1}$ was
\end{abstract}

detected after immersion in distilled water and CoregaTabs, demonstrating signs of alloy degradation. Peak at $2430 \mathrm{~cm}^{-1}$ after immersion in distilled water was observed. Conclusion: WWV at 30 vol \% is a promising low-cost alternative for the daily cleaning of removable dentures without altering surface properties and composition of removable partial denture components.

Key words: Removable denture, Vinegar, Raman spectroscopy.

Correspondence

Dr. Victor Pinheiro Feitosa, Dental School - Federal University of Ceará, Rua Monsenhor Furtado S/N, Bairro Rodolfo Teófilo, Fortaleza - CE, BRAZIL.

Phone: +55 85997361292

Email: lidiavaladas@gmail.com

DOI: 10.5530/jyp.2018.10.88

\section{INTRODUCTION}

Despite advances in dental implants, nowadays there is still a great number of rehabilitated people with removable dentures. ${ }^{1}$ Removable Partial Dentures (RPD) with clasps are widely used in developing countries because they are a simple and accessible method for the replacement of natural teeth for patients with low income. ${ }^{2}$ Given the large number of users of RPD, the correct cleaning of these prostheses becomes a relevant subject in the context of oral and systemic health. ${ }^{1,3-4}$ Indeed, this issue is of great relevance, once most of these patients are not able to purchase the expensive commercial RPD cleaning products.

RPDs as well as dental surfaces are prone to plaque deposition; ${ }^{5}$ therefore, constant education and care should be undertaken by the dentists in order to avoid damage to the soft tissues and to prosthetic components. The literature points out to a wide variety of materials and techniques for prosthetic hygiene such as: a) mechanical methods with by using toothbrushes and toothpastes or soaps, ultrasonic devices and microwave and b) chemical methods classified in alkaline peroxide, alkaline hypochlorite, acids, disinfectants and enzymes. ${ }^{6-7}$

Most investigations described cleaning methods for total removable dentures, which have no metallic component. Therefore, the outcomes cannot be extended to removable partial dentures with clasps that possess acrylic resin and metal. ${ }^{3}$ The ideal sanitizer product must be easy to use, effective in removing inorganic and organic deposits and stains, antimicrobial, non-toxic to patients, low cost and inert to prosthetics materials. ${ }^{8-10}$

In recent studies depicting promising products for the hygiene of removable dentures, White Wine Vinegar (WWV) solution might be highlighted for the disinfection of total dentures. ${ }^{11-12}$ These studies indicate the WWV as an effective alternative for the cleaning of removable dentures due to its fungicide activity, without causing damage to acrylic resin prosthesis. ${ }^{13}$ However, the effects of WWV on the components of RPDs with clasps simulating hygiene procedures have not been evaluated yet to our knowledge. Thus, the aim of this study was to evaluate the effect of WWV solution on the roughness, colour stability, weight loss and surface composition of RPDs components (metal, acrylic resin and artificial teeth). The hypothesis tested is that WWV solution induces no adverse effects on the surface properties of RPD compounds.

\section{MATERIALS AND METHODS}

The materials used in this investigation were a cobalt-chromium alloy (Degudent ${ }^{\oplus}$, Dentsply Brazil, São Paulo, Brazil), thermo-polymerized acrylic resin (Lucitone 550, Degudent ${ }^{\oplus} \mathrm{GmbH}$, Berlin, Germany), acrylic artificial tooth (VIPI, Pirassununga, Brazil), CoregaTabs (commercial and positive control, Stafford-Miller Industry, Rio de Janeiro, Brazil),

This is an open access article distributed under the terms of the Creative Commons Attribution-NonCommercial-ShareAlike 4.0 License, which allows others to remix, tweak, and build upon the work non-commercially, as long as the author is credited and the new creations are licensed under the identical terms. 
white wine vinegar (Minhoto, Raymundo da Fonte Industries, Paulista, Brazil) and distilled water as negative control.

To simulate a RPD with clasps, 30 rectangular specimens were prepared in a dental prosthesis laboratory (CLO Bill Rôla, Fortaleza, Brazil) measuring $38 \mathrm{~mm}$ x $18 \mathrm{~mm} \times 4 \mathrm{~mm}$ consisting of: cobalt-chromium alloy slab and acylic artificial tooth embedded in thermo-polymerized acrylic resin with reduced dimensions (Figure 1).

The experimental protocol used was based on a previous one described by Paranhos et al. 2007 with modifications. ${ }^{14}$ Initially, the thermopolymerized acrylic resin rectangles (Lucitone 550) were obtained from gypsum casts made of muffles. To obtain the molds, rectangular arrays of silicone were made measuring $38 \mathrm{~mm}$ x $18 \mathrm{~mm}$ x $4 \mathrm{~mm}$ with a lateral rectangular cavitation of approximately $8 \mathrm{~mm} \times 5 \mathrm{~mm} \times 3 \mathrm{~mm}$. The matrices were included in type IV stone gypsum (Densite, Dentsply, Petrópolis, Brazil) and after setting the gypsum, its surface was covered with insulating (Cel-Lac, SS White, Rio de Janeiro, Brazil). The counter muffle was filled with another portion of plaster gypsum that was poured into matrices. Then, the muffle was pressed for $40 \mathrm{~min}$ and then opened for removal of matrices. The acrylic resin was manipulated according to the manufacturer's instructions and inserted into the muffle in plastic stage of setting. After the setting and thermal regimen, rectangles were removed for finishing and polishing. For the metal portion of the specimens, wax patterns (GeoRenfert, GmbH, Hilzigen, Germany) were prepared in the lateral cavity of resin rectangles. Therefore, the wax was liquefied in electric plasticizing (BRAVAC, São Paulo, Brazil) at $70^{\circ} \mathrm{C}$ and then poured with dropper into respective space at each resin rectangle.

After cooling, wax patterns were removed from and the fused $\mathrm{Co}-\mathrm{Cr}$ alloy was manufactured by conventional casting methods (loss wax protocol). Square metal slabs were obtained and polished in polishing machine AROPOL-E (AROTEC, Cotia, São Paulo, Brazil) with increasing grits sandpapers (Norton, Saint Gobain, France) at $300 \mathrm{rpm}$ for $40 \mathrm{sec}$ and washed with distilled water in ultrasonic bath between each paper and at the end of the polishing. Afterwards, the metal slabs were set into the cavity of each resin rectangle with 1 drop of cyanoacrylate glue (Super-bonder ${ }^{\oplus}$, Henkel, São Paulo, Brazil).

The final procedure to produce the RPD with clasps specimens was the incorporation of acrylic tooth to the resin rectangles. The lingual surface of each tooth was abraded and flattened; they were fixed with the cyanoacrylate glue on the opposite side of the rectangular acrylic resins. The specimens were randomly identified and divided into three groups $(\mathrm{n}=10)$, with 30 times (30 cycles) immersion in each solution: 1) WWV: White Wine Vinegar solution diluted at $30 \mathrm{vol} \%$ in distilled water. The specimens were immersed in $200 \mathrm{~mL}$ of WWV solution for 30 min; ${ }^{11}$ 2) CT: Corega Tabs (CT) solution $(200 \mathrm{~mL})$ was prepared in accordance with the manufacturer's recommendations ${ }^{3}$ and the specimens were immersed for $5 \mathrm{~min} ;{ }^{11}$ 3) DW: The specimens were immersed in $200 \mathrm{~mL}$ of distilled water (DW) at room temperature for $30 \mathrm{~min}^{3}$ After immersion, the specimens of all groups were washed in tap water for $60 \mathrm{~s}$ and re-immersed in each refreshed solution for a further cycle of simulated chemical cleaning.

\section{Surface Analyses}

Specimens were analyzed before (T0) and after the immersions (T1). To check possible color changes of the specimens, the reflectance spectrophotometry technique was used with a digital spectrophotometer (VITA EasyShade ${ }^{\circledast}$ 4.0, VITA Zahnfabrik, BadSäckingen, Germany). The readings were made at the center of buccal surface of each tooth and the spectrophotometer was calibrated before each reading. ${ }^{13}$

To detect changes on roughness, Hommel Tester T1000 Perfilometer (Hommelwerke, GmbH, Schwennin-gen, Germany) was employed. Readings of mean roughness $(\mathrm{Ra})$ were performed on the metal, acrylic embedding resin and artificial tooth with three readings (to obtain the mean) at each substrate of each specimen $(n=10)$.

The chemical composition of the specimens' components (metal, acrylic resin and artificial tooth) was performed by means of Raman spectrophotometer (Xplora, Horiba, Paris, France) containing argon laser with $532 \mathrm{~nm}$ wavelength and $0.32 \mathrm{~mW}$ laser power. Magnifying 100X lens (Olympus) were used to carry out the focus in regions to be evaluated at each specimen. The Raman vibrational spectrum was obtained in the range of $100 \mathrm{~cm}^{-1}$ to $4000 \mathrm{~cm}^{-1}$ with 10 s exposure and 3 accumulations. All spectra were post-processed with normalization and baseline correction.

Finally, the evaluation of specimens' mass changes before and after immersions was undertaken by weighing each specimen in an analytical balance MARK 210A (BEL Equipamentos LTDA, Piracicaba, Brazil), with a $0.1 \mathrm{mg}$ sensitivity. After each analysis, the balance has been properly calibrated.

\section{Statistical analysis}

After passing normality and equal variance tests $(p>0.05)$, the data obtained on roughness, colour stability and mass variation experiments were analyzed by means of repeated measures ANOVA and Tukey's test $(\mathrm{p}<0.05)$ using SigmaStat 3.5 software (Systat Inc., San Jose, USA). Shade units of color analysis were transformed into numeric data according to the protocol of Peña and Ratón $2014^{13}$ in order to perform parametric statistical analysis.

\section{RESULTS}

\section{Color stability}

The outcomes of colour assay are presented in Table 1. Although there was some color change after immersions (especially for distilled water), no statistical differences were found $(\mathrm{p}<0.05)$. The mean color of all teeth specimens was $\mathrm{A} 3^{9}$ varying between $\mathrm{C} 2$ (7 in the scale of numbers) and B3 (represented by number 11).

\section{Surface roughness}

Table 2 presents the mean roughness in each period (T0 and T1). The statistical analysis depicted no difference between the cleaning solutions ( $p>0.05)$. Although the increased surface roughness after immersions in all solutions, such augment was not statistically significant.

\section{Surface Composition}

The micro-Raman spectra are shown in Figure 2. The analyses of $\mathrm{Co}-\mathrm{Cr}$ alloys depicted intense peak at $470 \mathrm{~cm}^{-1}$ corresponding to $\mathrm{Co}-\mathrm{Cr}$ metallic bond. This peak was present both before and after immersions in the three solutions (Figure 2A). However, it was less intense after immersion in distilled water and Corega Tabs. Furthermore, after distilled water immersion, a peak ascribed to chromium carbonate ${ }^{16}$ was identified at $2430 \mathrm{~cm}^{-1}$ (Figure 2B). The evaluation of thermo-polymerized acrylic

Table 1: Color analysis of the artificial teeth. Colors were showed in mean shade unit and representative numbers (average \pm standard deviations).

\begin{tabular}{|c|c|c|}
\hline $\begin{array}{l}\text { Color average } \\
\text { (Shade unit) }\end{array}$ & Before immersion & After Immersion \\
\hline Water & A3 $(8.6 \pm 4.0)$ & B3 $(11.4 \pm 3.9)$ \\
\hline Corega & $\mathrm{A} 3(9.3 \pm 5.6)$ & D3 $(9.6 \pm 4.8)$ \\
\hline Vinegar & C2 $(7.2 \pm 4.2)$ & A3 $(9.1 \pm 6.1)$ \\
\hline
\end{tabular}

*There was no statistical difference between the immersion solutions before ( $p>0.05)$ or after $(\mathrm{p}>0.05)$ the immersion. 
Table 2: Outcomes (means \pm standard deviations) of roughness $(\mu \mathrm{m})$.

\begin{tabular}{ccccccc}
\hline \multirow{2}{*}{ Roughness $(\mathrm{Ra})$} & \multicolumn{3}{c}{ Before immersion } & \multicolumn{3}{c}{ After Immersion } \\
\cline { 2 - 7 } & Metal & Resin & Tooth & Metal & Resin & Tooth \\
\hline Water & $0.0136 \pm 0.0028$ & $0.0103 \pm 0.0009$ & $0.0109 \pm 0.0021$ & $0.0197 \pm 0.0039$ & $0.0178 \pm 0.0049$ & $0.0171 \pm 0.0061$ \\
Corega & $0.0143 \pm 0.0048$ & $0.0112 \pm 0.0021$ & $0.0127 \pm 0.0050$ & $0.0203 \pm 0.0062$ & $0.0171 \pm 0.0041$ & $0.0179 \pm 0.0037$ \\
Vinegar & $0.0118 \pm 0.0033$ & $0.0103 \pm 0.0009$ & $0.0096 \pm 0.0012$ & $0.0178 \pm 0.0040$ & $0.0181 \pm 0.0026$ & $0.0181 \pm 0.0026$ \\
\hline
\end{tabular}

${ }^{*}$ There was no statistical difference among groups $(p>0.05)$.

Table 3: Results of mass analyses before and after immersion in distilled water (DW), Corega Tabs $^{\circledR}$ (CT) and White Wine Vinegar (WWV).

\begin{tabular}{ccc}
\hline Weight $(\mathbf{g})$ & Before immersion & After Immersion \\
\hline DW & $8.33 \pm 0.01 \mathrm{~B}$ & $8.36 \pm 0.03 \mathrm{~A}$ \\
CT & $8.08 \pm 0.05 \mathrm{~A}$ & $8.06 \pm 0.06 \mathrm{~B}$ \\
WWV & $8.46 \pm 0.03 \mathrm{~A}$ & $8.44 \pm 0.04 \mathrm{~B}$ \\
\hline
\end{tabular}

* Different capital letters indicate statistical difference $(p<0.05)$ between before and after immersion. Analyses among solutions at each period did not show statistical differences $(p>0.05)$.

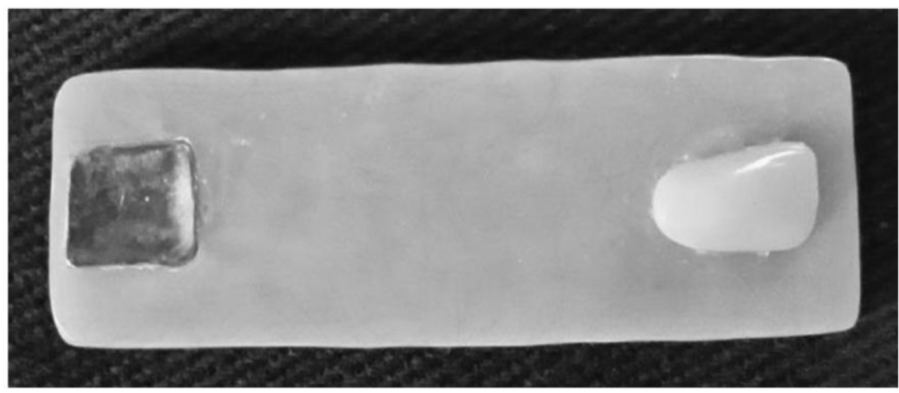

Figure 1: Representative image of the specimen prepared with Co-Cr alloy and artificial acrylic tooth embedded in thermo-polymerized acrylic resin.

resin depicted for all groups a peak at $800 \mathrm{~cm}^{-1}$ ascribed to PMMA polymer. Also, after immersion in distilled water, the spectrum of the acrylic resin presented an additional peak at $2430 \mathrm{~cm}^{-1}$ (Figure 2C) showing deposition of chromium carbonate. The results of Raman analyses of artificial teeth were very similar to those of acrylic embedding resin thereby demonstrating the peak at $800 \mathrm{~cm}^{-1}$ in all conditions and the presence of the additional peak at $2430 \mathrm{~cm}^{-1}$ only for specimens immersed in distilled water (Figure 2D).

\section{Mass Variation}

Specimens' mass outcomes did not show statistically significant difference between the solutions ( $p>0.05)$. However, after immersions, there has been an increase in the mass of specimens $(p<0.001)$ in contact with distilled water and significant reduction for the CoregaTabs ${ }^{\oplus}$ and White Wine Vinegar solutions ( $\mathrm{p}=0.042$ and $\mathrm{p}=0.002$, respectively). Table 3 presents the results obtained in the analysis of specimens' mass.

\section{DISCUSSION}

Few in vitro studies have investigated the use of chemical cleansers with focus on possible adverse effects on the components of the RPDs with clasps, especially on their metal Co-Cr structure. ${ }^{3,15-16}$ Nowadays, there is great interest for substances economically viable for all patients to assist in the cleaning of dentures. This study was conducted to evaluate the ef-
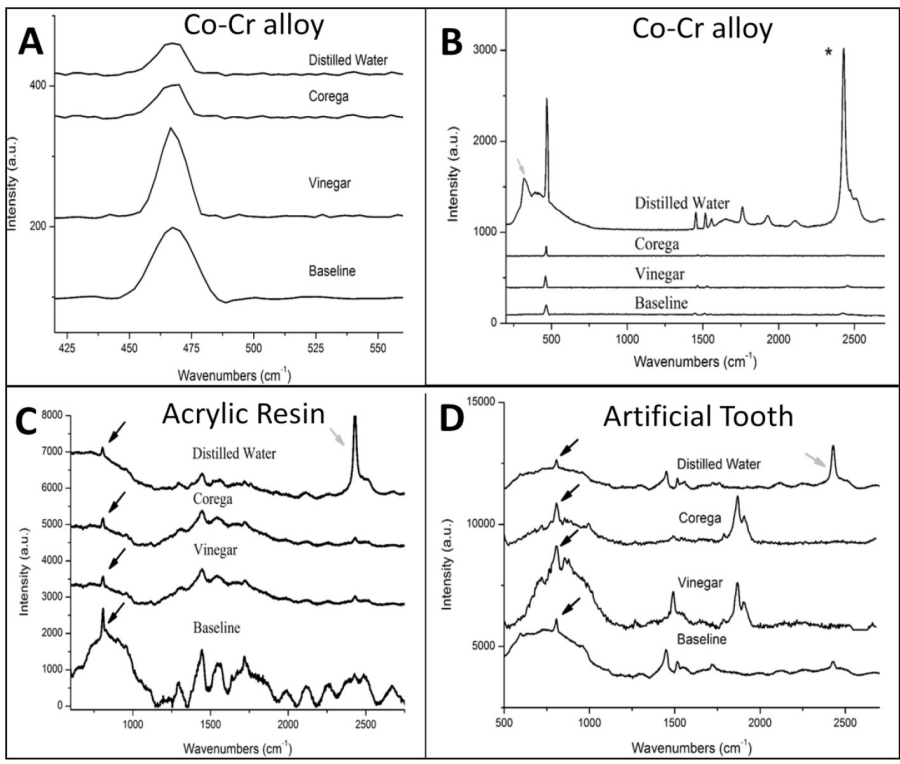

Figure 2: Spectra from micro-Raman spectroscopy survey. (A) - Selected range (225-550 $\left.\mathrm{cm}^{-1}\right)$ spectra showed the $470 \mathrm{~cm}^{-1}$ peak ascribed to $\mathrm{Co}-\mathrm{Cr}$ alloy. Note the height reduction after immersions in distilled water and Corega Tabs solution thereby indicating degradation of the metallic component by these solutions. No difference was detected after WWV immersion in comparison with baseline (pre-immersion) spectrum. (B) - Further selected range $\left(2300-2600 \mathrm{~cm}^{-1}\right)$ spectra of $\mathrm{Co}-\mathrm{Cr}$ alloy are presented. The arrow indicates peak at $2430 \mathrm{~cm}^{-1}$ peak, representative of chromium carbonate. (C) - Spectra of thermo-polymerized acrylic resin. Black arrows indicate $800 \mathrm{~cm}^{-1}$ peak of poly-methyl-methacrylate (PMMA) polymer; the gray arrow indicates 2430 $\mathrm{cm}^{-1}$ peak of chromium carbonate. (D) - Spectra from the survey of artificial teeth. Black arrows indicate $800 \mathrm{~cm}^{-1}$ peak of PMMA and gray arrow depicts $2430 \mathrm{~cm}^{-1}$ peak of chromium carbonate.

fects of white Wine Vinegar influence on the components of RPDs with clasps, since such solution has demonstrated to be an efficient cleanser for dentures, ${ }^{11,17-18}$ due to its antimicrobial activity. ${ }^{20}$ Indeed, WWV solution displayed the slighter effects on surface properties of substrates evaluated in the present study. Nevertheless, due to the minor effects on mass change, the study hypothesis that WWV induces no negative effects on RPDs components needs to be rejected.

In a previous investigation, ${ }^{17} \mathrm{WWV}$ presented positive results in $50 \mathrm{vol} \%$ and neat concentrations for the disinfection of removable total dentures (RTDs) thereby showing antifungal action against strains of Candida albicans. Those concentrations were different from the one used in this study (30\%), which also presented antimicrobial activity in the study of Andrade, et al. ${ }^{11}$ Their investigation ${ }^{11}$ evaluated the effects of vinegar solutions at $10 \%$ and $30 \%$ on C. albicans in vitro attached on the surface of acrylic resin of RTDs and it was observed significant reduction in the log $\mathrm{UFC} / \mathrm{mL}$ of $C$. albicans on the comparing to the control. Therefore, we 
established in the present study to assess the immersion in 30\% WWV solution, $30 \mathrm{~min} /$ day for 30 days as undertaken previously.,11

Lower concentration (2.5\%) of vinegar was also evaluated on strains of C. albicans. ${ }^{21}$ The authors surveyed surface roughness of two denture base acrylic resins and found higher roughness caused by vinegar at $2.5 \%$ for Acropars resin, which was significantly higher than other solutions tested $(0.5 \%$ sodium hypochlorite, $5 \%$ sodium bicarbonate and CoregaTabs ${ }^{\oplus}$ ). The previous report ${ }^{21}$ showed contrasting results in comparison with the present outcomes. Such difference may likely be explained by the different brands of resin used (the other acrylic resin was not affected by vinegar solution) and the common vinegar (more aggressive) employed. White Wine Vinegar possesses lower concentration of acids in comparison with common vinegar. Regarding the roughness of acrylic resin, the study of Da Silva, et al. ${ }^{22}$ used $100 \%$ vinegar as a disinfectant solution and did not depict significant roughness change for vinegar immersion, corroborating with the findings of the present study. The dental materials roughness analysis is of foremost importance, because the surface roughness may affect directly or indirectly the adherence of microorganisms. ${ }^{3}$ Felipucci et al. ${ }^{3}$ found the presence of metal staining only in samples immersed in sodium hypochlorite with no staining for immersions in distilled water and CoregaTabs ${ }^{\otimes}$ solution. Visual inspection (10X magnification stereomicroscopy) of specimens in the present study showed no signs of metal staining after all immersion regimens.

To our knowledge, there were no investigations that analyzed the influence of chemical cleaning solutions on the color of artificial teeth in removable partial dentures with clasps. The studies have emphasized, over the years, the colour changing on acrylic resin, likely with the use of sodium hypochlorite as cleanser and its whitening action on acrylic resin. In this study, we analyzed the WWV action on artificial teeth colour and, although there was some color change, that was no statistically significant differences after immersions in distilled water, Corega tabs and WWV solution. Further studies in this direction should be designed to assess color changes after longer periods of immersion in different cleansers.

Concerning the mass variations, an increase in the weight of specimens immersed in distilled water and a decrease in those immersed in CoregaTabs ${ }^{\oplus}$ and WWV solutions were observed (Table 3). Corroborating with our results, other studies also observed an increase and decrease in the mass of the specimen immersed in distilled water and CoregaTabs solution respectively., ${ }^{3,8}$ Indeed, water sorption promoted by distilled water and chromium carbonate deposition (Figure 2B) might be suitable explanations for the increase, whilst the alkaline solution of CoregaTabs may facilitate the release of linear polymers thereby reducing the weight. In the case of WWV solution, it was possible to observe a discrete mass reduction, similar to CoregaTabs ${ }^{\oplus}$. The same interpretation with acidic release of linear polymer chains might be related to WWV solution.

In order to check possible changes in the chemical surface composition of the specimens, we employed Raman spectroscopy (RS). Literature reveals that the RS is highly reliable method to evaluate the composition of dental materials. Moreover, its use offers advantages as it dispenses preparations or manipulations of all kinds of specimens. In addition, changes in materials may suggest the occurrence of important chemical phenomena such as corrosion in the case of metals where the release of ions as a function of the $\mathrm{pH}$ of the medium, with the formation of a protective oxide film on the surface. ${ }^{19,23}$ It was found in the micro-Raman analysis that Co-Cr alloys depicted the presence of a peak at $470 \mathrm{~cm}^{-1}$ before and after immersion in all solutions. According to the literature, this peak refers to the Co-Cr metal bond. ${ }^{24}$ However, the specimens' analysis after immersion in distilled water revealed the noteworthy presence peak at $2430 \mathrm{~cm}^{-1}$. According to the literature, ${ }^{25}$ this peak is ascribed to chromium carbonate inorganic bond. One may infer that formation of chromium carbonate occurs due to the reaction equilibrium reaction between carbon dioxide gas (from the air) and distilled water, which leads to the formation of carbonate ions and slight reduction in the $\mathrm{pH}$. Those carbonates have affinity with slightly rusty chrome present on the surface of the metal alloy. In this regard, a chemical reaction may occur between them promoting the formation of chromium carbonate salts, which were deposited on the surface of the metal alloy (Figure 2B) and the surrounding regions like acrylic resin (Figure $2 \mathrm{C}$ ) and artificial teeth (Figure 2D). This phenomenon might be interpreted as a corrosive process that occurs only with distilled/deionized water not occurring with ion-containing saliva in the oral cavity. Those peaks were not observed in the readings made on Co-Cr alloy of specimens immersed in 30vol\% WWV and CoregaTabs. The analysis on thermo-polymerized acrylic resin and artificial teeth, before and after immersion in all solutions, showed the presence of a peak at $800 \mathrm{~cm}^{-1}$ that, according to the literature, ${ }^{23}$ corresponds to the PMMA covalent bond. The present results suggest that WWV at $30 \%$ and CoregaTabs ${ }^{\oplus}$, even presenting higher acidity or alkalinity than distilled water, can cause a protective effect hindering the formation of chromium carbonate salts, thus, reducing possible deleterious effects on the RPDs with clasps components.

\section{CONCLUSION}

Within the limitations of the present investigation, it may be concluded that white Wine Vinegar solution is a feasible alternative to the hygiene of removable partial dentures with clasps, when diluted at $30 \%$ concentration and for $30 \mathrm{~min}$ per day in the form of soaking solution. However, more studies are needed in order to clarify the action of acetic acid from WWV on weight loss of specimens.

\section{ACKNOWLEDGEMENT}

Sincere thanks to the Laboratory of Postgraduate Research and Laser Centrer in Dentistry Bill Rola, places of this research.

\section{CONFLICT OF INTEREST}

The authors declare no conflict of interest.

\section{REFERENCES}

1. Peracini A, Andrade IMD, Paranhos HFO, Silva CHLD, Souza RFD. Behaviors and hygiene habits of complete denture wearers. Braz Dent J. 2010;21(3):247-52.

2. Preshaw PM, Walls AWG, Jakubovics NS, Moynihan PJ, Jepson NJA, Loewy Z. Association of removable partial denture use with oral and systemic health. J Dent. 2011;39(11):711-9.

3. Felipucci DNB, Davi LR, Paranhos HFO, Bezzon OL, Silva RF, Pagnano VO. Effect of different cleansers on the surface of removable partial denture. Braz Dent J. 2011;22(5):392-7.

4. Davi LR, Peracini A, Ribeiro NDQ, Soares RB, Silva CHLD, Paranhos HFO, et al. Effect of the physical properties of acrylic resin of overnight immersion in sodium hypochlorite solution. Gerodontology. 2010;27(4):297-302.

5. Wagner B, Kern M. Clinical evaluation of removable partial dentures 10 years after insertion: success rates, hygienic problems and technical failures. Clin Oral Investig. 2000;4(2):74-80

6. Paranhos HFO, Silva LCH, Souza RF, Cruz PC, Freitas KM, Peracini A. Effects of mechanical and chemical methods on denture biofilm accumulation. J Oral Rehabil. 2007;34(8):606-12.

7. Buergers R, Rosentritt M, Schneider BW, Behr M, Handel G, Hahnel S. Efficacy of denture disinfection methods in controlling Candida albicans colonization in vitro. Acta Odontol Scand. 2008;66(3):174-80.

8. Catão CDS, Ramos INC, Silva NJM, Duarte SMO, Batista AUD, Dias AHM. Chemical substance efficiency in the biofilm removing in complete denture. RevOdontol UNESP. 2007;36(1):53-60

9. Silva LCH, Paranhos HFO, Mello PC, Cruz PC, Freitas KM, Macedo LD. Rising of the instructions degree and of materials and methods of hygiene used by complete dentures users. Rev Odontol UNESP. 2006;35(2):125-31.

10. Chittaranjan B, Taruna, Sudhir, Bharath. Material and methods for cleaning the dentures. Indian J Dent Adv. 2011;3(1):423-7. 
11. Andrade IPB, Junqueira JC, Faria ISD, Santos SSFD, Rego MAD, Jorge AOC. Vinegar effects in Candida albicans after the adherence in-vitro on the heatactivated acrylic resin. Braz Dent Sci. 2010;11:91-8.

12. Azuma CRDS, Cassanho ACA, Silva FCD, Ito CYK, Jorge AOC. Antimicrobial activity of acetic acid of different types and origins on Candida albicans. Rev Pos-Grad. 2006;13:164-7.

13. Peña VA, Ratón ML. Randomized clinical trial on the efficacy and safety of four professional at-home tooth whitening gels. Oper Dent. 2014;39(2):136-43.

14. Ribeiro DG, Pavarina AC, Giampaolo ET, Machado AL, Jorge JH, Garcia PPNS. Effect of oral hygiene education and motivation on removable partial denture wearers: Iongitudinal study. Gerodontology. 2009;26(2):150-6.

15. Cruz PC, Andrade IM, Peracini A, Souza GMC, Silva LCH, Souza RFD, et al. The effectiveness of chemical denture cleansers and ultrasonic device in biofilm removal from complete dentures. J Appl Oral Sci. 2011;19(6):668-73.

16. Lucena FSCD, Cavalcanti IMG, Cury AADB. Efficacy of denture cleansers in reducing microbial counts from removable partial dentures: a short-term clinical evaluation. Braz Dent J. 2013;24(4):353-6.

17. Felipucci DN, Davi LR, Paranhos HF, Bezzon OL, Silva RF, Barbosa JF, et al. Effect of different cleansers on the weight and ion release of removable partial denture: an in vitro study. J Appl Oral Sci. 2011;19(5):483-7.

18. Davi LR, Felipucci DN, Souza DRF, Bezzon OL, Lovato SCH, Pagnano VO, et al. Effect of denture cleansers on metal ion release and surface roughness of denture base materials. Braz Dent J. 2012;23(4):387-93.

19. Shmalz G, Garhammer P. Biological interactions of dental cast alloys with oral tissues. Dent Mater. 2002;18(5):396-406.

20. Yildirim BAZ, Peker I, Akca G, Celik I. In vitro antifungal evaluation of seven different disinfectants on acrylic resins. BioMed Res Int. 2014;51:90-8.

21. Nematollahi F, Saghiri MA, Mobayeni MR. Evaluating the Effect of Four Chemical Disinfectants on Surface Roughness of Acrylic Resin Denture Base Material (in vitro evaluation). J Res Dent Sci. 2014;11(3):160-6.

22. Silva FCD, Kimpara ET, Mancini MNG, Balducci I, Jorge AOC, Koga ICY. Effectiveness of six different disinfectants on removing five microbial species and effects on the topographic characteristics of acrylic resin. J Prosthodont. 2008;17(8):627-33.

23. Wang R, Tao J, Yu B, Dai L. Characterization of mulltiwalled carbon nanotubepolymethyl methacrylate composite resins as denture base materials. J Prosthet Dent. 2014;111(4):318-26.

24. Flint CD, Greenough P. The use of luminescence spectroscopy to determine infrared and raman inactive fundamentals: the $\zeta 2 \mathrm{u}$ vibrational frequencies of the $\mathrm{Cr}(\mathrm{CN}) 3-6$ ion. Univ of Calif. 1978;14:489-90.

25. Genge MJ, Jones AP, Price GD. An infrared and raman study of carbonate glasses: implications for the structure of carbonatite magmas. Geoch Cos A. 1995;59(5):927-37.

Article History: Submission Date : 16-06-2018; Revised Date : 11-07-2018; Acceptance Date : 06-08-2018.

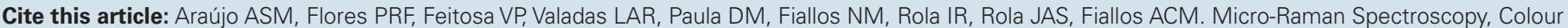
Stability, Roughness and Mass Variation of Removable Partial Dentures after Cleansing with White Wine Vinegar. J Young Pharm. 2018;10(4):399-403. 